\title{
Dewatering Parameters in a Screw Press and their Influence on the Screw Press Outputs.
}

\author{
Authors : Bouchaib El idrissia (Bouchaib.el.idrissi@uqtr.ca), Éric Loranger ${ }^{\mathrm{a}}$ \\ (Eric.Loranger1@uqtr.ca), Robert Lanouette (robert.lanouette@uqtr.ca), Jean Pierre \\ Bousquet $^{\mathrm{b}}$ (jean-pierre.bousquet@valmet.com), Mark Martinez ${ }^{\mathrm{c}}$ (mark.martinez@ubc.ca) \\ a I2E3 - Institut d'Innovations en Écomatériaux, Écoproduits et Écoénergies, à base de biomasse. Trois- \\ Rivières, Canada. \\ $b$ Valmet USA inc.-fibre business line. Duluth, USA. \\ c University of British columbia, Pulp and Paper Center. Vancouver, Canada \\ *Corresponding author: bouchaib.el.idrissi@uqtr.ca
}

\begin{abstract}
A Thune SP23 screw press dewatering parameters were studied. The dewatering efficiency was affected more by the rotational speed and the pulp properties. The counterpressure affects dewatering near the discharge end, and it was observed to influence the outlet consistency and filtrate flow rate of Kraft, which has much longer fibres and fewer fines compared to TMP and BCTMP.
\end{abstract}

The feed stock freeness and consistency are very important variables to consider in the screw press performance. The freeness reflects the degree of drainage, which is an important parameter to consider when optimising the screw press, while the feed consistency is a parameter of the fibre-fibre contact degree. The pulp properties, especially the fines content and fibre flexibility are also two very important parameters that affect the screw press performance.

This study was to provide an insight of the screw press performance and to show the complex effect of the operational parameters on the dewatering characteristics. Using three different pulps, Kraft and TMP softwood fibres and a BCTMP hardwood fibres, we have shown that the fines content and fibre properties are two dominant properties that should be highly considered when operating a screw press.

Keywords: Dewatering, Screw press, wood pulp, water removal.

\section{Introduction}

Dewatering is a very important unit operation in the pulp and paper industry. Such operation can be achieved to obtain an optimum consistency for consecutive process steps (refining, dispersion, bleaching), or it can be employed to remove undesirable non-fibrous dissolved materials and contaminants. In the dewatering technology we find a variety of machines and the most used are the belt press, the centrifuge and the screw press. The screw press is more advantageous in the pulp and paper dewatering, offering a very good dewatering rate with a compact machine and much quieter compared to the belt press or the centrifuge. Also, the screw press uses less energy to produce a cake as dry as the centrifuge and the belt press, plus the screw press maintenance is easier.

The dewatering starts as soon as the stock is fed to the screw press and the removed water is termed filtrate. The screw press consists essentially of a threaded screw rotating in a 
fixed perforated screen cylinder. The pitch of the screw as well as the depth of the channel may be fixed or varying along the axis of the screw. At the discharge end, there is a zone without screw thread, known as the plug zone. The screw press designs vary widely; we find screw presses with constant or retracting pitch, single or double threaded, continuous or disrupted flights [1]. The root diameter may be constant or gradually increasing towards the discharge end.

Although the wide use of the screw presses in the pulp and paper industry, few studies have analysed the dewatering of pulp stock. Egenes et al. [1-3] concluded that as the material moves forward in an axial direction, there is an initial filtration taking place on the inner surface of the perforated barrel, if the feed is a free-flowing suspension. Then the cake is consolidated by compression starting from the point where the channel is filled by the cake and creating a compression zone. A main cause for the rather peculiar behaviour of the fibre web in the screw press is the characteristics of the fibre network. Already at about $1 \%$ consistency the fibres interact and intertwine to form networks possessing the properties of solid materials. The compressive yield strength of the networks rises with the second power of the consistency $[4,5]$. This point is beneficial for the ability of the barrel plate to hold the web avoiding it just to fill the channel and rotating with the screw.

Feeding pressure, rotational speed and the applied counter pressure can be varied independently. The consistency of the feed suspension can be as low as approximately 2 $\%$, although 10 to $15 \%$ feed stock can be handled as well [2]. On this basis, the objective of this study is to depict the influence of the operational parameters on some of the screw press outputs, also to characterise the effect of varying feed consistency and the effect of having a suspension with different freeness. This study will help to understand how these parameters affect the dewatering in the screw press and if the screw press performance can be optimised. The study includes three types of pulp with different properties to compare the dewatering performance on a wide range of fibre properties.

\section{Material and Methods}

\subsection{Materials}

In this study, a Thune SP23 screw press was used with $230 \mathrm{~mm}$ barrel diameter and 1.2 $\mathrm{mm}$ holes diameter that represent $27.5 \%$ of the open area. Figure 1 shows the characteristics of the press. We used three pulps having the following characteristics ( on the basis of average length-weighted): the first pulp is a softwood Kraft, with a $2 \mathrm{~mm}$ fibre length and $27 \mu \mathrm{m}$ width, containing $27 \%$ of fines and a crowding factor ${ }^{1}$ [5-7] of 285 as an indicator of the fibres tendency to network. The second pulp is a hardwood Bleached Chemi-ThermoMechanical Pulp (BCTMP), having a $0.81 \mathrm{~mm}$ fibre length, the fibres width is $28.6 \mu \mathrm{m}$, fines content of $52 \%$ and a crowding factor of 69 . The third pulp is a softwood Thermo-Mechanical Pulp (TMP), with a $0.91 \mathrm{~mm}$ fibre length, and a $33.9 \mu \mathrm{m}$ fibre width, containing $61 \%$ of fines and having a crowding factor of 54 . The crowding factor was defined by Kerekes $[5,6]$ showing there is a direct correlation to the number of the contact per fibre. The crowding factor was used by Soszynski [7] to implement flocculation regimes. In dilute regime $(\mathrm{N}<1)$, fibres are free to move relative to each other, but they may undergo a chance collision. In the semi-concentrated regime $(1<\mathrm{N}<60)$, more

\footnotetext{
${ }^{1}$ The crowding factor, $\mathrm{N}$, represents the number of fibres in a spherical volume of diameter equal to the length of a fibre. It is used to characterise fibres flocculation in water suspension.
} 
97 collisions occur between fibres with formation of transitory flocs. For the concentrated 98 regime $(\mathrm{N}>60)$, coherent flocs are present and higher shear strength is required to break 99 them. So, the higher the crowding factor the better the fibre aggregation occurring. 100 According to the crowding factor values for the three pulps, the suspension entering the 101 screw press is above the gel point $[8,9]$.

102 


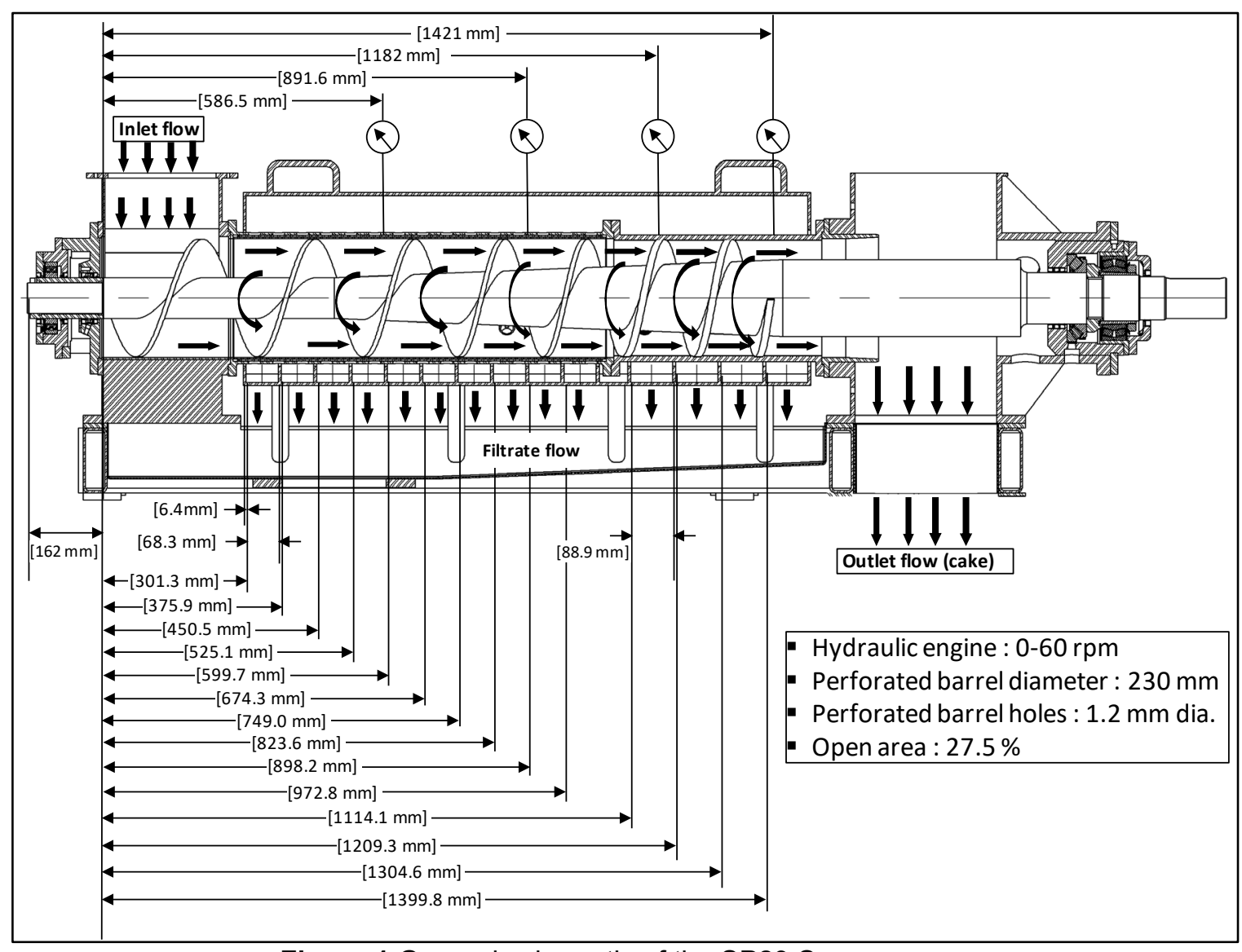

Figure 1.General schematic of the SP23 Screw press.

\subsection{Methods}

The study included pulp suspensions of different fibre raw materials, pulping methods, pulp refining levels, consistency, etc. Effect of the operational variables like rotational speed, feed, and cone pressure were also included. The trials were organised using a Central Composite experimental design [10], and for each parameter we used the central data point to produce graphics containing only 3 points, the $-1,0$ and +1 values of the design while maintaining other variables at level 0 . i.e.: for the rotational speed effect, all the other parameters are fixed in level 0 values, while the rotational speed is varying from -1 to +1 levels (Table 1 ).

The screw press performance was evaluated using six characteristics. The filtrate flow rate and the filtrate consistency are two indicators of the water removal. The outlet consistency and the production indicate the capacity of the screw press, and the energy consumption to estimate the power the drive motor must provide. Finally, we have chosen to install four pressure sensors along the screw press, as we noticed that the pressure along the screw press does not change much in the first three sensors, only the sensor four mean pressure will be an indicator of the degree of compression close to the discharge end. For each performance, we represent only the graphs with noticeable variation, the graphs with almost constant values are summarised as tables.

We should mention that we did not use the same values for the rotational speed. When operating with high rotational speed, the screw press could not handle the dewatering of BCTMP and TMP, so to continue the experimental design we had to make some changes in the rotational speed values. 
Table 1. Operational parameters values.

\begin{tabular}{|c|c|c|c|c|c|c|c|c|c|c|c|c|c|c|c|}
\hline \multirow{2}{*}{$\begin{array}{l}\text { Pulp } \\
\text { Levels } \\
\end{array}$} & \multicolumn{3}{|c|}{$\begin{array}{c}\text { Rotational } \\
\text { speed (rpm) }\end{array}$} & \multicolumn{3}{|c|}{$\begin{array}{c}\text { Consistency } \\
(\%)\end{array}$} & \multicolumn{3}{|c|}{ Freeness $^{3}(\mathrm{~mL})$} & \multicolumn{3}{|c|}{$\begin{array}{l}\text { Feed pressure } \\
\text { (kPag) }\end{array}$} & \multicolumn{3}{|c|}{$\begin{array}{c}\text { Counter- } \\
\text { pressure (kPag) }\end{array}$} \\
\hline & -1 & $\mathbf{0}$ & +1 & -1 & $\mathbf{0}$ & +1 & -1 & $\mathbf{0}$ & +1 & -1 & 0 & +1 & -1 & $\mathbf{0}$ & +1 \\
\hline Kraft & 22 & 33 & 44 & 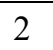 & 3 & 4 & 176 & 292 & 464 & 10 & 20 & & 200 & 300 & 400 \\
\hline ВСТMP & 9 & 19 & 44 & 0 & 3.3 & 3.8 & 151 & 262 & 328 & 8 & 13 & 30 & 200 & 300 & 400 \\
\hline TMP & 10 & 22 & 34 & 2 & 2.8 & 3.6 & 137 & 197 & 276 & 4 & 13 & 18 & 200 & 300 & 400 \\
\hline
\end{tabular}

131

\section{RESULTS AND DISCUSSION}

\subsection{Filtrate flow rate}

The filtrate flow rate is influenced by the screw rotational speed and the freeness as shown in graphs in Figure 2. The consistency, the feed pressure, and the counter-pressure have no influence, as noticed in the table in Figure 2.

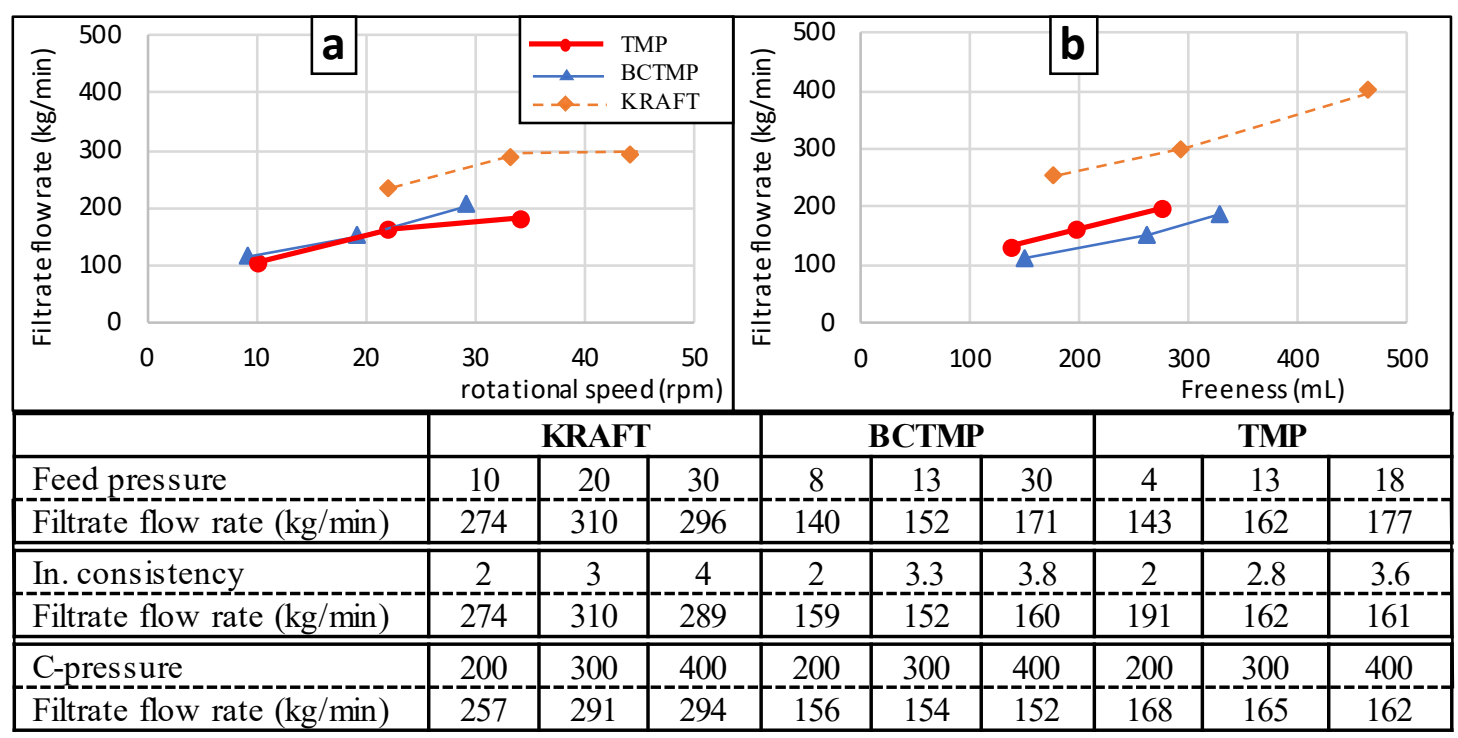

Figure 2. Filtrate flow variation

Increasing the rotational speed will increase the axial velocity of the web, thus the screw will scrape off the formed web rapidly allowing better drainage as a thinner web is developed on the screen cylinder (Figure 2-a). This effect is noticed for the three pulps. The only difference is noticed for TMP and Kraft, which at higher rotational speed there seem to level off in terms of filtrate flow rate. When increasing the rotational speed, the screw flights will push the web rapidly to the discharge end. If we continue to increase the rotational speed, the filtration process will not be completed in the press. This will cause an increase in the filtrate flow rate, a sudden drop in the pressure will occur at the discharge end and, an abrupt drop of the outlet consistency, as mentioned by Egenes et al [1].

\footnotetext{
2 Pulp consistency or, more properly, "concentration" is defined as the weight in grams of oven-dry fiber in $100 \mathrm{~g}$ of pulp-water mixture (Method Tappi 240 om-93).

${ }^{3}$ The freeness of pulp is designed to give a measure of the rate at which a dilute suspension of pulp ( $3 \mathrm{~g}$ of pulp in $1 \mathrm{~L}$ of water) may be drained (Method Tappi 227 om-99).
} 
Softwood Kraft has long flexible fibres. Softwood TMP and hardwood BCTMP have rigid fibres because of their high yield. When the fibres are flexible they tend to intertwine causing water to be retained in the web and hard to drain, but the fines content is also a critical factor in drainage. The fines can block the pores in the fibre network, explaining why even Kraft with more flexible fibres, would still have higher drainage, because no fines are blocking the pores. TMP and BCTMP have almost the same fibre length and fines content, but the rotational speed for TMP was $3 \mathrm{rpm}$ higher than that for BCTMP and the feeding consistency of TMP was slightly lower than BCTMP, which explains why we have TMP filtrate flow rate more important than BCTMP. Another factor is that the Kraft fibres are larger than the perforated barrel hole diameter, which can lead to an accumulation of the fibres on the perforated barrel, thus reducing the filtrate flow rate.

The feed pressure affects slightly the filtrate flow rate. There is an average increase of $30 \mathrm{~kg} / \mathrm{min}$ (about 10\% variation) when increasing the pump pressure from 8 to $30 \mathrm{kPag}$ for BCTMP, and almost the same variation can be noticed for Kraft and TMP. The feed pressure influences the axial speed of the web. When we increase the pressure, the formed web is pushed faster to the discharge end, but not as important as when increasing the rotational speed, thus the pressure effect is negligible compared to the rotational speed. The rotational speed increase is more important, since when increasing the speed, the flights are disturbing the mat that is formed on the screen plate, which would decrease the dewatering resistance. In other words, the web stays longer in the first phase of dewatering where the mat is established. The counter-pressure has no effect on TMP and BCTMP but for Kraft, the filtrate flow rate increases when increasing the counter-pressure. Kraft pulp fibres are twice longer than BCTMP and TMP, also containing twice less fines, which explains this difference. Having longer fibres, Kraft can dewater more when applying higher pressure near to the discharge end. BCTMP and TMP fines tend to plug the interspace between fibres, thus reducing drainage.

Increasing the feeding consistency implies an increase in the fibre-fibre contact, thus a compact web is rapidly formed giving a lower filtrate flow rate. From collected data in the table (Figure 2), we notice that the feed consistency variation imparts a slight effect on Kraft. The filtrate flow rate increases slightly when increasing the consistency from $2 \%$ to $4 \%$. On the other hand, for TMP we notice a decrease in the filtrate flow rate when the feeding consistency increases from $2 \%$ to $3.6 \%$, but there is no variation for BCTMP. The different behaviour between the three pulps is due to the fibre properties. Kraft is from softwood fibres with $27 \%$ fines content, about two times less than that of BCTMP and TMP and with a high crowding factor which helps Kraft fibres to aggregate well compared to TMP and BCTMP, thus the web is less plugged allowing better drainage. The fact to have long fibres, the fibre-fibre contact effect is not that important compared to TMP, which is also a softwood but containing $61 \%$ of fines, and fibres half shorter than those of Kraft. For BCTMP we notice almost no change because of the nature of the hardwood fibres. Hardwood fibres are more rigid, meaning that they tend to collapse less, hence increasing the feed consistency does not change the fibres chances to intertwine, and form a web that can block the water from draining. Maybe this effect can be noticed when operating with a much higher consistency value. Finally, when comparing TMP and BCTMP, they show to have close response to the operational parameters with very close filtrate flow rate even if they are from two different wood type, but it seems that the fines content and their close crowding factor are more important than the tree species. 
The rotational speed and freeness are the main factors that affect the filtrate flow rate, other factors have almost no impact on BCTMP and TMP and a slight impact on Kraft,

204 the differences are explained by the fibres properties, especially fines content and fibre 205 length.

\subsection{Filtrate consistency}

As the filtrate contains mostly fines and short fibres, we added here a graph showing the filtrate consistency variation with the suspension initial fines content. For the three pulps, increasing rotational speed will increase the filtrate consistency (Figure 3-a). Obviously, increasing the rotational speed of the screw tends to increase the forwardmoving velocity of the web. The screw flight scrapes off the formed web more often, reducing the thickness of the web on the screen barrel, thus the filtrate consistency will increase. Kraft and BCTMP are both from softwood, which may explain why their filtrate consistencies are identical and lower than that of hardwood TMP. Also, it indicates that the fines content in the pulp does not dictate the fines content in the filtrate. From Figure 3-e, we can notice that even if the suspensions have different fines content, the filtrate consistency is identical for the three pulps. Even if we may expect that TMP and BCTMP maybe have much higher filtrate consistency, it seems that the fines and short fibres seal the fibre-fibre interspace, resulting to have more important pressure near to the discharge end (Figure 3-e) and having a clear filtrate. The filtrate consistency decreases when increasing the pulp freeness. When the freeness increases, water drains easily, and the web is formed rapidly, so we reach a compact web, blocking fibres quickly in the press. Simard et al. [11] studied the dewatering of a mechanical fibre stock of $450-700 \mathrm{~mL}$, which generates a filtrate of $0.1-0.15 \%$ consistency, whilst filtrate from stocks of lower freeness 90-120 mL have consistencies between 0.25-0.4\%. The same tendency is observed for the three pulps studied. 

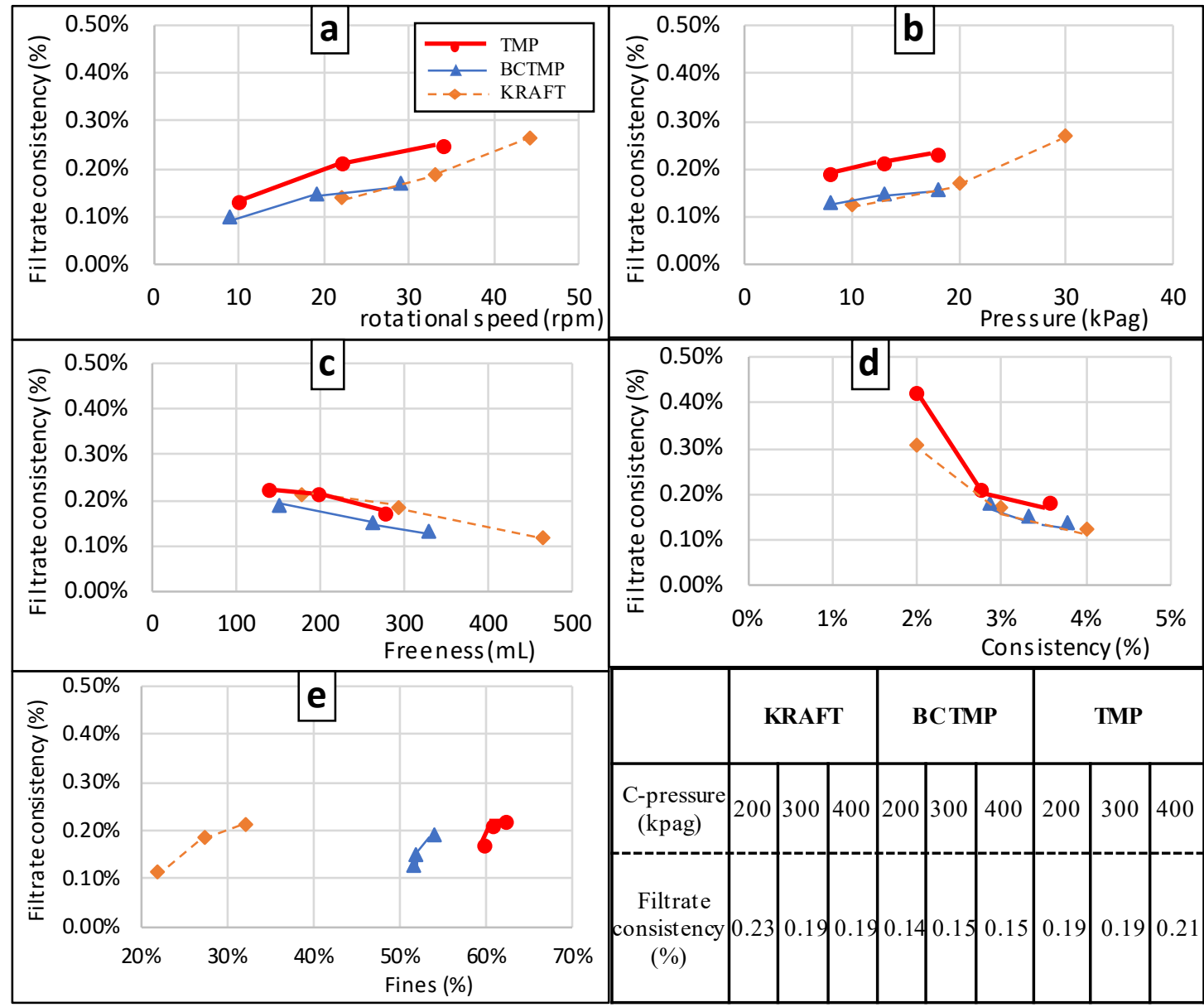

Figure 3. Filtrate consistency variation.

Increasing the feeding pressure will increase the filtrate consistency (Figure 3-b), simply because the filtrate velocity through the cylinder perforations increases, and fibres and fines are forced through the holes, because of a combined effect of pressure and fluid drag forces. The variation is slow for BCTMP and TMP which contains more fines that seal the fibre-fibre interspaces and more pressure is needed to express more water and push the fines through the perforated cylinder holes. The counter-pressure is applied near to the discharge end, and at this point the web contains the properties of a compact solid material, thus the pressure applied at this point does not affect much the filtrate consistency.

The higher the feeding consistency, the lower the filtrate consistency. For obvious reason, at high feeding consistencies, the suspension is more compact, and the fibre network is rapidly formed, blocking the fibres to slip from the perforated barrel. When the feeding stock has a very low consistency, the drainage is very important, carrying fines and short fibres through the perforated cylinder. In Figure 3-d for consistency graphs, we can notice the important variation when operating at $2 \%$ stock consistency and $3 \%$. When operating at $2 \%$, the suspension is a free flowing at the feed end of the press, thus the filtration occurs immediately when entering the screw press. When the inlet consistency increase to $3 \%$, the fibre/fibre contact is more important and if we take into consideration its effect on the crowding factor, the fibres aggregate giving a clear filtrate. 


\subsection{Outlet consistency}

The outlet consistency is mainly affected by rotational speed for the three pulps with no significant effect of other parameters (Figure 4).

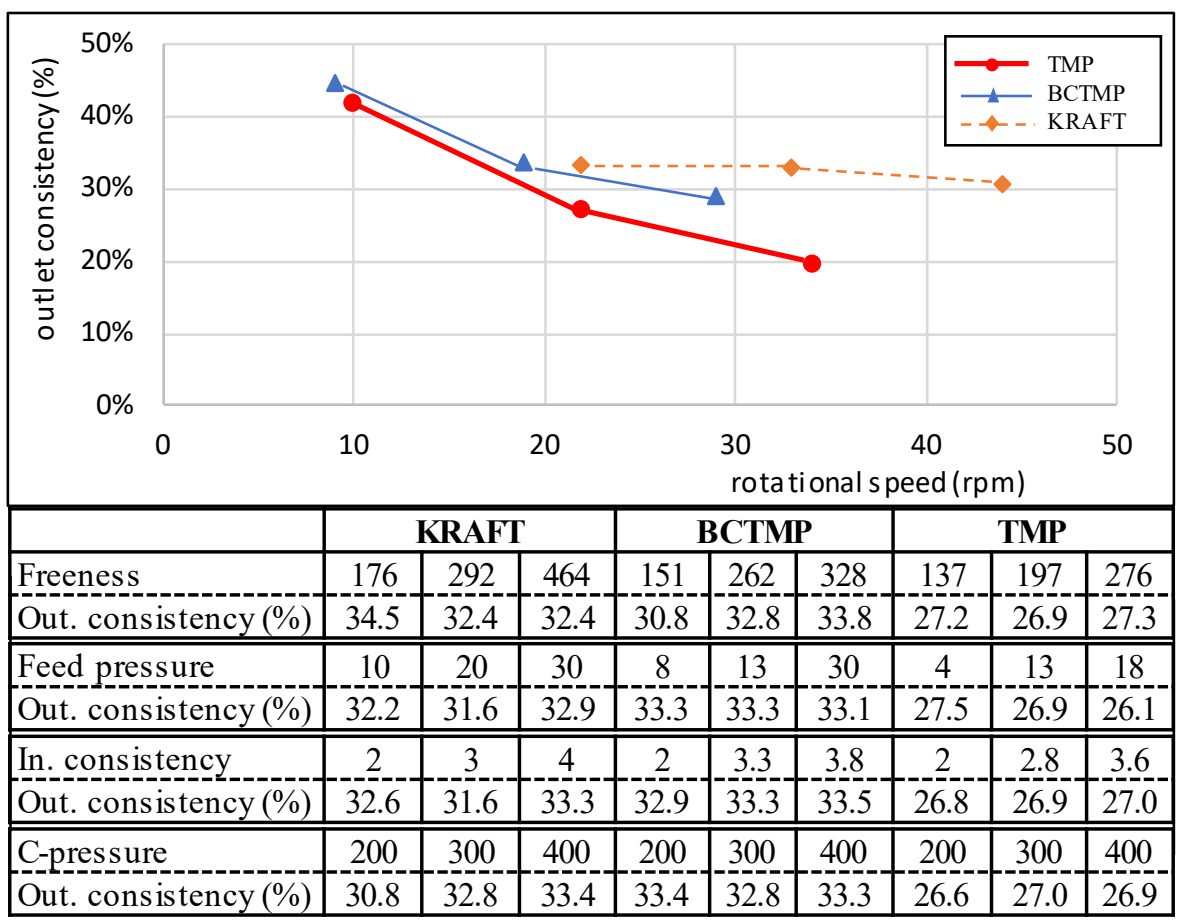

Figure 4. Outlet consistency variation.

259

260

261

262

263

264

265

266

267

268

269

270

271

272

273

274

275

276

277

278

279

280

Increasing the rotational speed of the screw will increase the forward-moving velocity of the web, thus reducing pressing time in the screw press. So, it is very reasonable that the consistency of the discharged pulp will decrease with increased rotational speed. The rotational speed effect is less important for Kraft. Having long fibres, Kraft dewater rapidly compared to TMP and BCTMP, hence even when increasing the rotational speed, the outlet consistency is less affected. The screw press will discharge the fibrous material at very high consistencies. Hence, it is not surprising that the shearing action of the rotating screw can impart some curl to the fibres [12]. Page et al. [13] note an increase in curl index by some $0.2-0.3$ points during the pressing of a low-yield unbleached softwood sulfite pulps in screw presses. Wieters [14] found that no "undesirable" characteristics had been transmitted to the pulp by the screw press. We should keep in mind that fibres susceptibility to curl varies, low yield pulp fibres curl easy, high yield pulps less.

We have a slight increase for Kraft pulp, when increasing the counter-pressure. The counter pressure only affects the pressure in the plug zone of the press, and Kraft has long fibres, with less fines that can block water from draining.

\subsection{Screw press production}

The screw press production calculated on basis of oven dry metric ton per day (odmt/d), is affected by the rotational speed, the feed stock consistency and the freeness (Figure 4) and Figure 6 shows the percentage of the outlet dry flow 

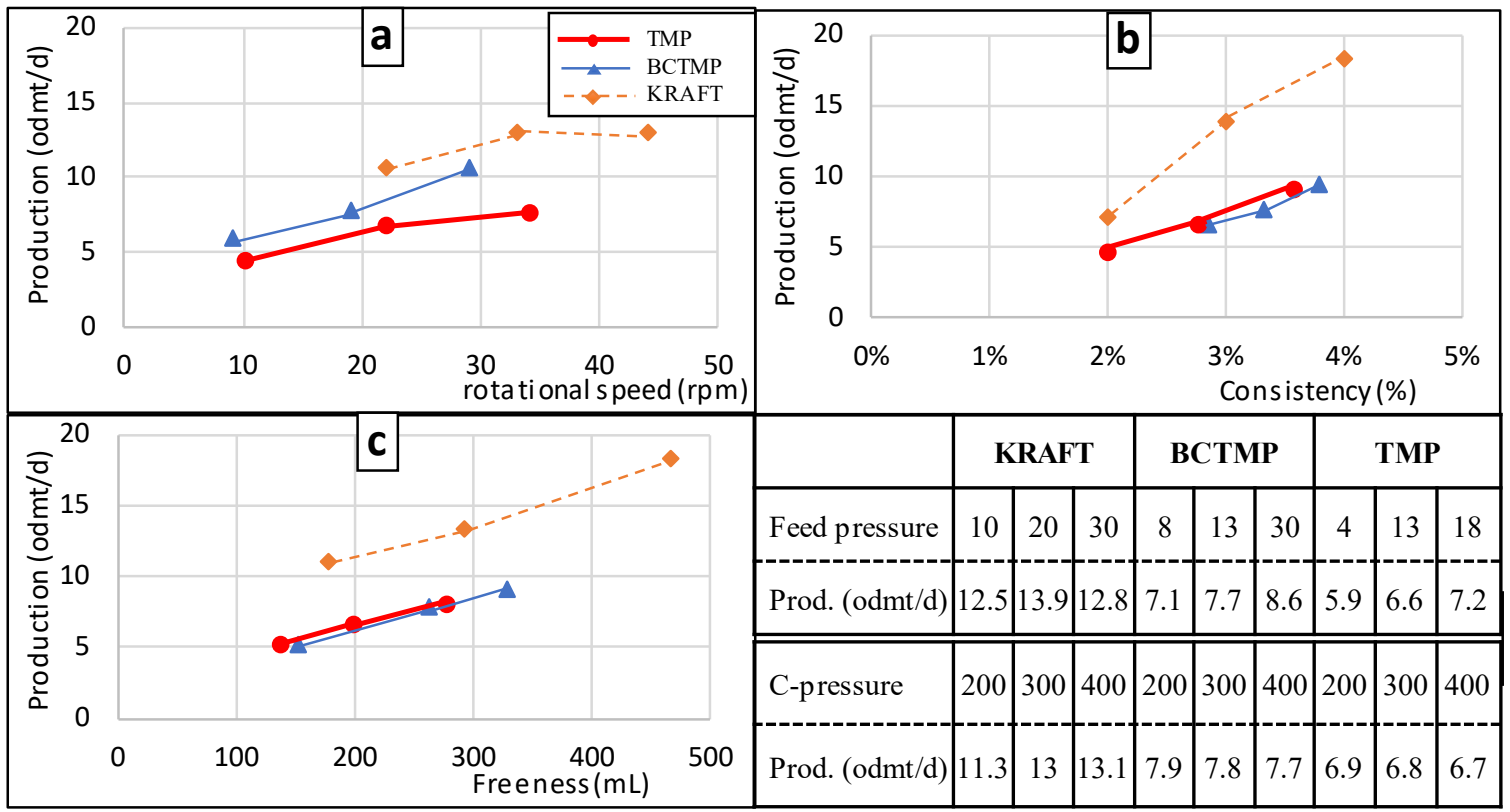

Figure 5. Screw press production variation
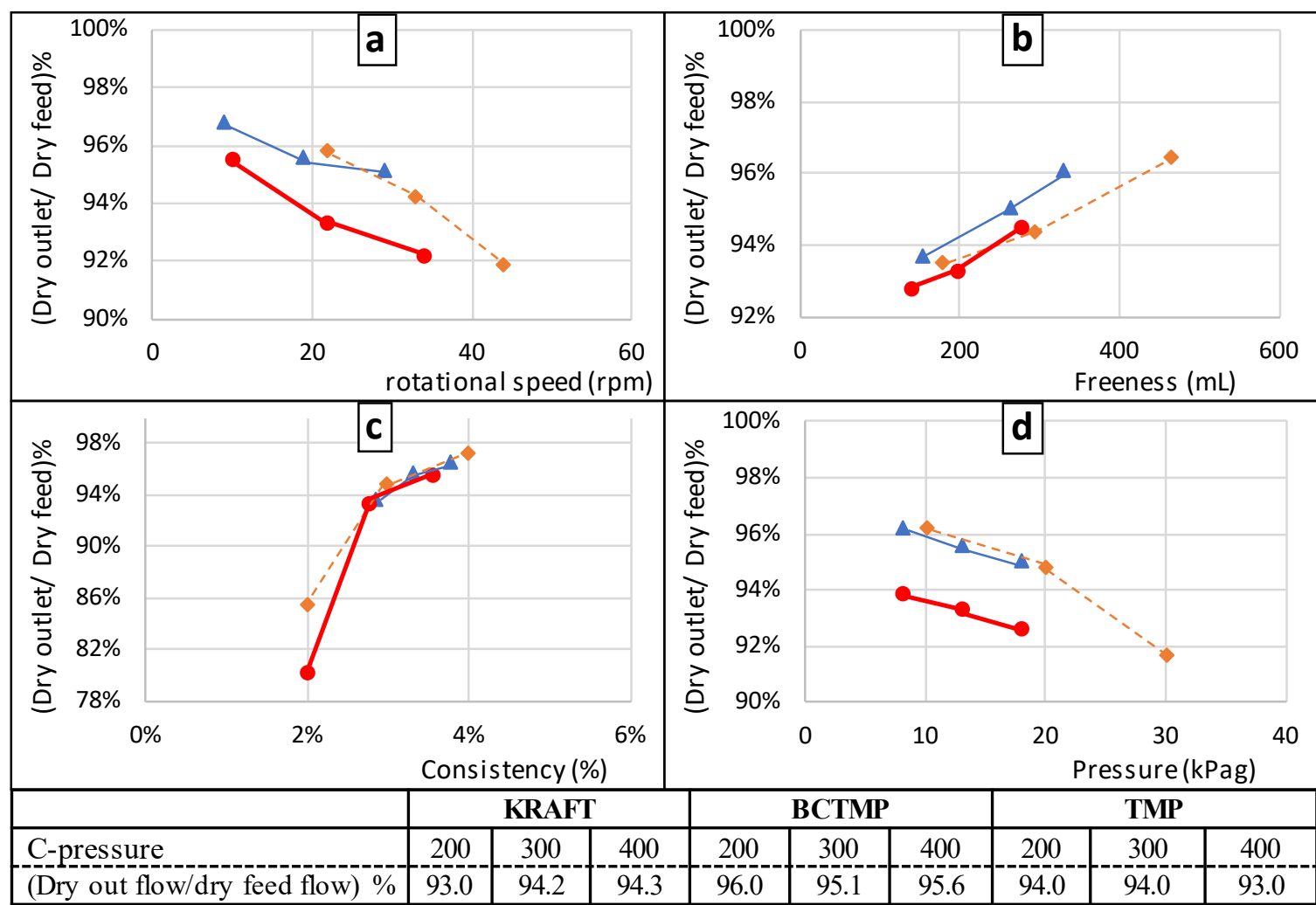

\begin{tabular}{|l|c|c|c|}
\hline \multicolumn{3}{|c|}{ Consistency (\%) } \\
\hline & \multicolumn{3}{|c|}{ KRAFT } \\
\hline C-pressure & 200 & 300 & 400 \\
\hline (Dry out flow/dry feed flow) \% & 93.0 & 94.2 & 94.3 \\
\hline
\end{tabular}

Figure 6. (Dry out. flow/Dry feed flow) \% variation.

As discussed before, increasing the rotational speed will increase the filtrate flow rate (Figure 2-a), and the pulp is pushed rapidly, giving opportunity to the pump to inject more pulp to the press. Thus a very important inlet flow and an outlet flow, meaning an increase in the screw press production, but the dry conversion decreases as noticed in Figure 6-a. For instance for Kraft, increasing the rotational speed from $20 \mathrm{rpm}$ to $44 \mathrm{rpm}$ the dry conversion decreases from $96 \%$ to $92 \%$. Kraft seems to be affected by the rotational speed until $30 \mathrm{rpm}$ then the production is stabilised, and this observed for TMP up to 20 
rpm. This can be explained by the fibre flexibility as Kraft and TMP are both softwoods.

It is evident when increasing the feed stock consistency, we will increase the production (Figure 5). This effect is more evident for Kraft. As we discussed before, increasing the feed stock consistency, implies an increase in the fibres entanglement and their ability to intertwine, this explains why the production increases more for Kraft compared to TMP and BCTMP. On the other hand, we notice in Figure 6-c that when operating at $2 \%$ TMP feed consistency, only $78 \%$ of the dry feed is collected at the discharge end and $22 \%$ is collected in the filtrate, that is reduced to only $6 \%$ when the feed consistency is $3 \%$.

The feed pressure and the counter-pressure has almost no effect on the production. As we can notice from the table in Figure 5, increasing the feed pressure from $4 \mathrm{kPag}$ to $18 \mathrm{kPag}$ we gain only about $1.3 \mathrm{odmt} / \mathrm{d}$ in production for TMP. Almost the same variation is observed for BCTMP and Kraft. On the other hand, the counter-pressure has more effect on Kraft compared to TMP and BCTMP. As the counter-pressure affects dewatering near the discharge zone, and knowing that Kraft pulp with longer fibres, is more permeable than BTMP and TMP, this explains why it affects Kraft and has no effect on TMP and BCTMP.

\subsection{Screw press energy consumption}

The energy consumption represents here the energy consumed by the screw press to produce one $\mathrm{kg}$ of dry pulp. It is calculated as follow:

$$
\text { Energy consumption }=((\text { Torque } \times \text { Rot.speed }) / 9.5488) /(\text { Dry out. flow } \times 60)
$$

The torque of the screw press was calculated from the hydraulic pressure in the screw press.

The energy decreases when increasing the rotational speed, the freeness and the consistency, and almost constant when increasing the counter-pressure and the feed pressure (Figure 7). We added the graph of the outlet consistency versus the energy to check the friction effect (all the operational parameters are fixed, except the rotational speed). 


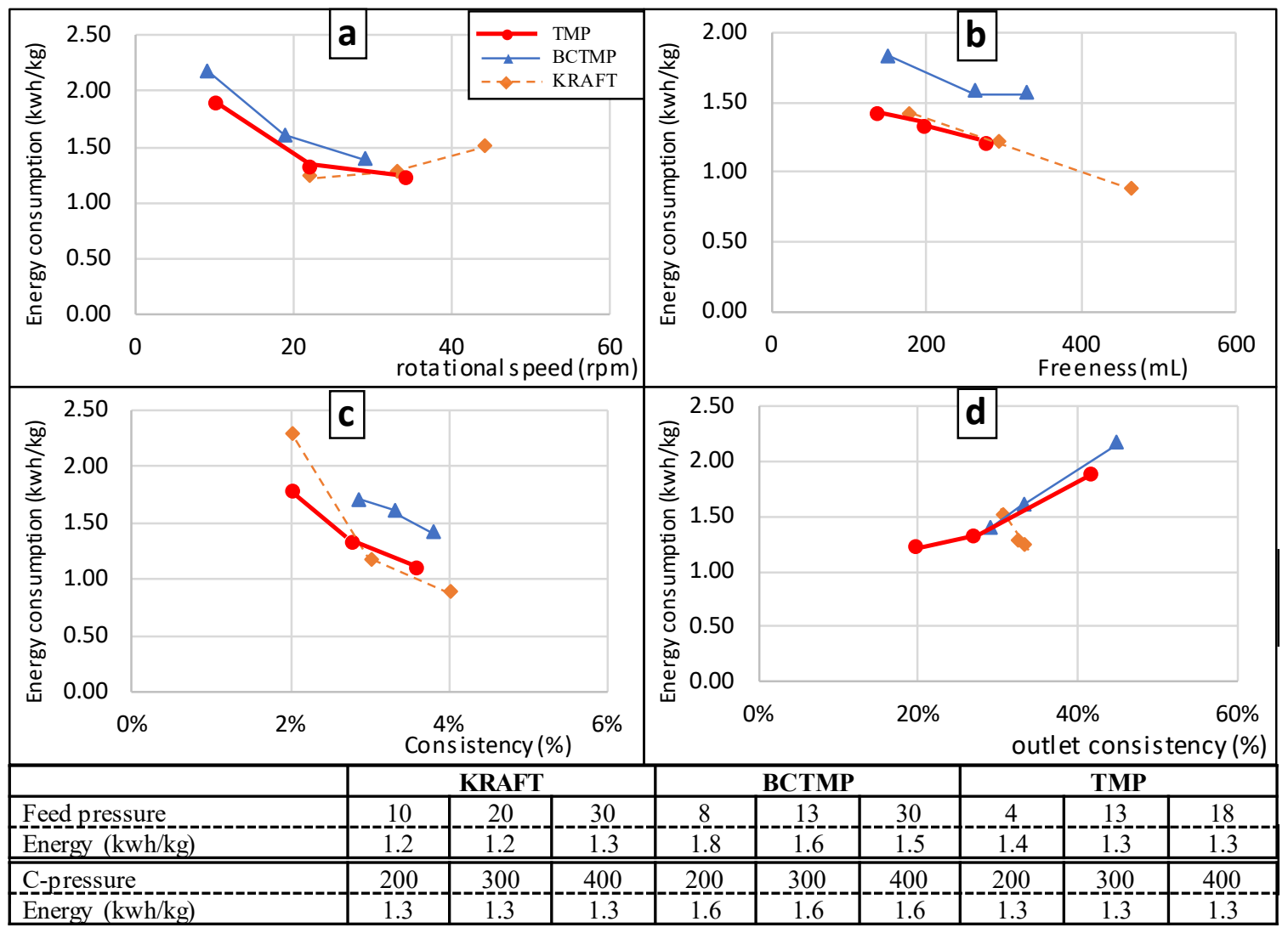

Figure 7. Energy consumption variation.

As we noticed in Figure 5-a, the production increases when increasing the rotational speed, the consistency and the freeness. An increase in the production means an increase in the inlet flow rate and an increase in the discharge flow rate as well. In other words, an increase in the inlet flow rate means an increase in the feed pump pressure, which reduces the pressure contribution of the screw drive motor, thus a decrease in the energy consumption when increasing the rotational speed, the consistency and the freeness (Figure 7). The same variation is observed for the three pulps studied except for Kraft, when increasing the rotational speed, we have an increase in the energy consumption as well. This can be explained by the fact that Kraft drains rapidly, and we have a compact web close to the feed end, which means we start to have the frictional effects as soon as the feed stock enter the screw press, and when increasing the rotational speed, the screw drive motor contributes more to move the compact web. Analysing the energy consumption vs. the outlet consistency, and as expected, when the outlet consistency increases, the friction coefficient is higher, so the energy consumption is more important except for Kraft, where we notice the opposite. As we discussed before, the outlet consistency increase when decreasing the rotational speed and the pulp has enough time to drain by filtration, so, the motor drive force contributes more to the movement of the compact web in a short distance near to the discharge end, which explains why the energy consumed is less when having an important outlet consistency for Kraft.

\subsection{Sensor 4 mean pressure}

The pressure at any point in the channel is generated as a complex balance between the feed and the discharge die pressure, the drag forces on the material in the channel and 
353 its flow response, is slip properties, the drainage resistance of the suspension and the permeability and compressibility characteristics of the formed particle web. Also, the geometrical shape of the channel affects the pressure level. In our study, we have installed four pressure sensors along the screw press, to be able to track the pressure variation. The pression was almost constant until the sensor 3 then we start to notice a notable increase towards the discharge end (Figure 8), for obvious reason, because it is in the compression zone. The pressure basket variation along the screw axis is mainly relevant in the last section of the screw press. So, we present just the variation for sensor 4 near to the discharge end (Figure 9).

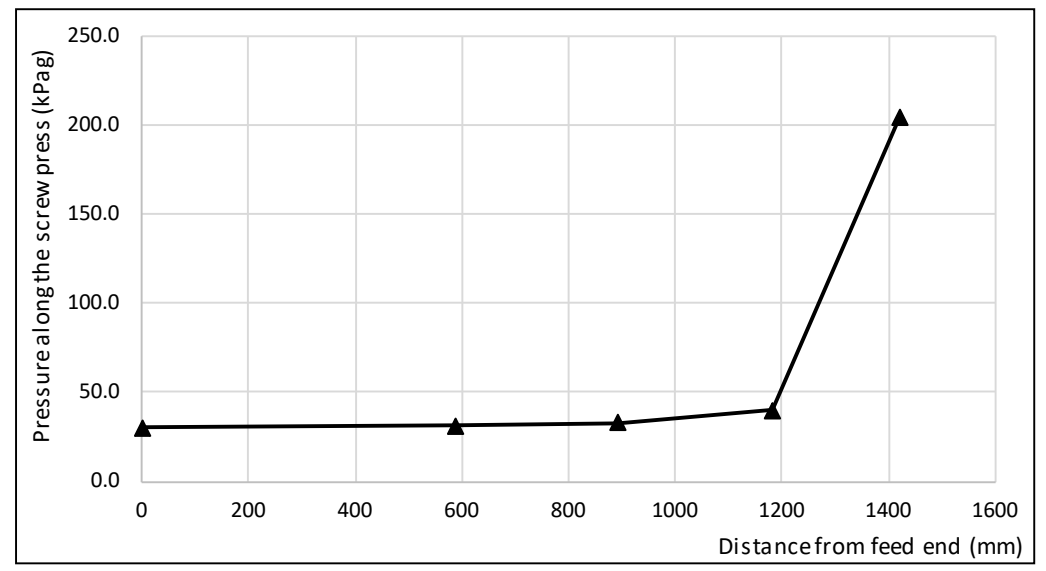

Figure 8. Pressure variation along the screw press.

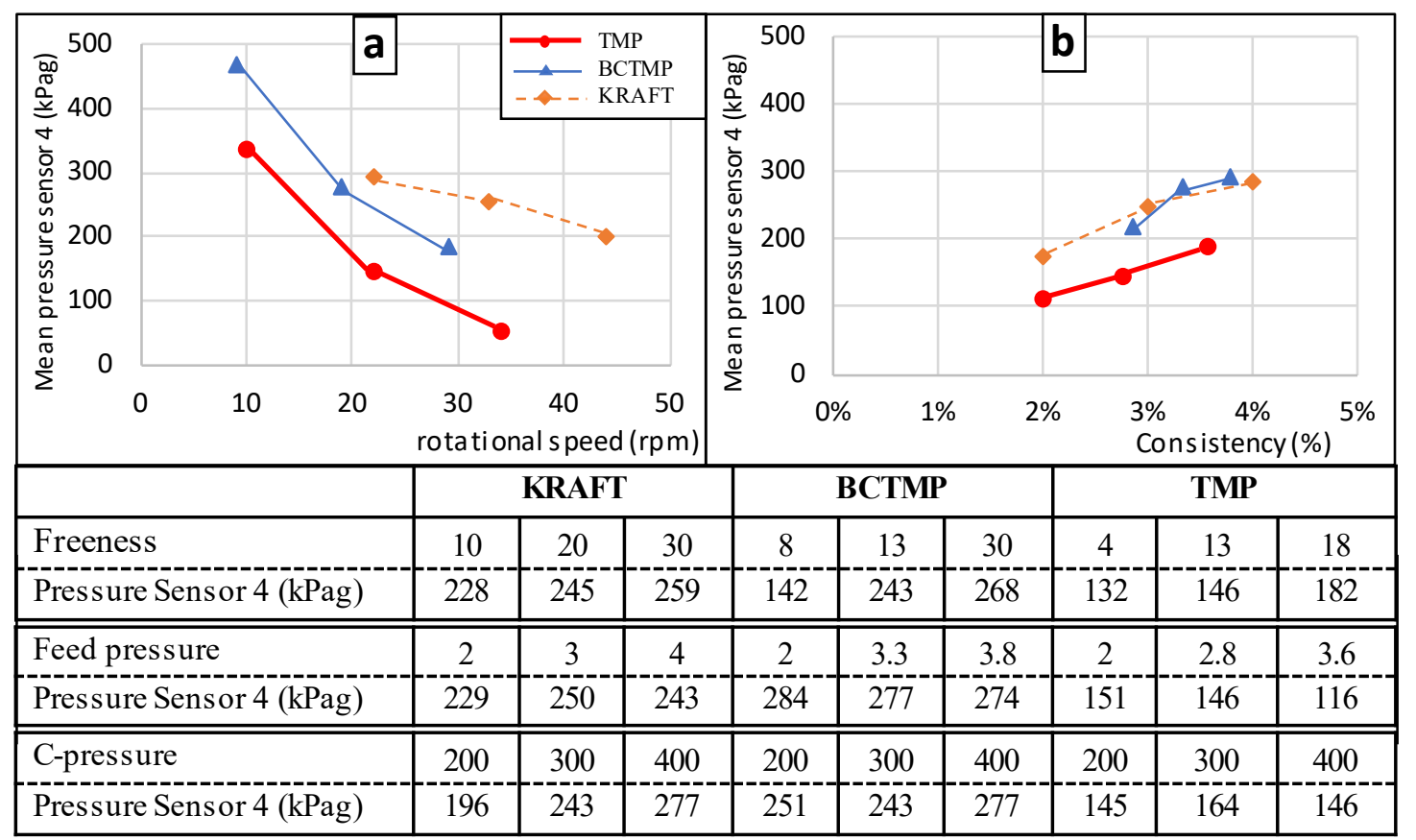

Figure 9. Sensor 4 mean pressure variation.

The pressure in the compression zone is more related to the rotational speed. When increasing the rotational speed, the screw flights will push the web rapidly towards the discharge end, thus the transition from the filtration process to the compression will happen closer to the discharge end. The rotational increase will not give enough time for a pressure 
373 build-up, thus, the pressure near to discharge end decreases when increasing the rotational 374 speed as noticed in Figure 9-a. The variation is more important for TMP and BCTMP, 375 Kraft is more permeable compared to the other two pulps, meaning even if when we 376 increase the rotational speed, Kraft still dewater better forming a compact web and enough 377 pressure is formed to dewater more near to the discharge end. On the other hand, for 378 BCTMP and TMP, if we increase the rotational speed more, it seems we can end up having 379 a liquid web in the discharge end (Figure 4). Also, we should consider that when operating 380 with low rotational speeds, we have higher outlet consistency, giving a higher pressure in 381 sensor 4.

The feed stock consistency has also an effect on the pressure build-up near to the discharge end, and it is obvious when increasing the feed consistency. As the web is formed, we have more fibres per unit of volume. In other words, production rate is increased (Figure 5-b) and the compression ratio is increased, adding the drag forces applied as well as the screw flights movement will exert enough force to increase the pressure in the screw press. This effect is observed for the three pulps at almost the same degree.

For the other parameters, we have the freeness that affects more BCTMP, and this difference can be due to the fibre flexibility as BCTMP is a hardwood, Kraft and TMP are both softwoods. We also have a more important effect of counter-pressure on Kraft compared to BCTMP and TMP, knowing that Kraft is more permeable than BCTMP and TMP, the counter-pressure helps Kraft pulp to dewater more, and an increased consistency near to the discharge end implies an increase in the pressure build-up. 


\section{CONCLUSIONS}

When increasing the rotational speed, the filtrate consistency and flow rate will increase. The increase in the filtrate flow rate will allow free space in the screw press, thus more suspension is pumped into the press which increases the screw press production but reduces the quality of the produced pulp having lower consistency. The inlet flow rate is increased when increasing the rotational speed, meaning an increase in the feed pump, which reduces the specific energy consumption by reducing the contribution of the screw drive motor. The three pulps reacted the same way to the rotational speed variation, and the degree of the variation is mainly due to the fibre length and flexibility.

The freeness is the pulp capacity of draining, thus when feeding a pulp with high freeness, the filtrate flow rate is more important, but the filtrate consistency decreases. As the filtrate flow rate increases, the inlet flow increases and the screw press production as well. The three pulps react the same way to the freeness variation, but the fines content is a very critical parameter.

The pressure affects mainly the filtrate. When increasing the pressure, filtrate flow rate increases. The pressure with the drag forces applied on the formed web in the press pushes short fibres and fines through the perforated cylinder which increases the filtrate consistency. Kraft is more affected by the pressure variation because of the low fines content compared to BCTMP and TMP, the fines tend to seal the fibre interspaces, thus reducing drainage and blocking fibres from in the press.

The increase in the feed consistency raises the fibre-fibre contact and when the fibres are flexible, they intertwine and entangle, thus the filtrate consistency decreases. When operating with high feed consistencies, the pump must apply high pressure to push the pulp which reduces the contribution of the screw drive motor, thus reducing the screw press energy consumption, and the pressure near the discharge end is more important due to the rapidly compact formed web.

The counter-pressure effect can be noticed only near the discharge end. For the three pulps we notice the counter-pressure affect only Kraft. Having long fibres and less fines, Kraft can dewater better even when we have a compact pulp, it is more permeable and most of short fibres and fines were removed in the first sections of the press, thus even near the discharge end Kraft can still dewater well.

Finally, we should notice that the crowding factor and the fines content are two very important pulp properties to consider when dewatering. The crowding factor has a crucial role in the fibre loss in the filtrate. When the crowding is very high, the fibres aggregate allowing a clear filtrate and reducing the fibre loss, giving a dry pulp at the discharge.

\section{ACKNOWLEDGEMENTS}

The financial support from the Natural Sciences and Engineering Research Council of Canada (NSERC) is gratefully acknowledged. 


\section{REFERENCES}

[1] T. Egenes, T. Helle, Flow characteristics and water removal from pulp suspensions in a screw press, Journal of pulp and paper science 18 (1992) J93-J99.

[2] T. Egenes, T. Helle, P. Bendiksen, G. Hegstad, Removal of water and contaminants from ONP stocks in a screw press, Pulp \& paper Canada 96 (1995) 40-46.

[3] T.H. Egenes, T. Helle, Transport and drainage processes in a screw press, as affected by material characteristics, 78th Annual Meeting - Technical Section, Canadian Pulp and Paper Association, Preprints, 1992, pp. 173-181.

[4] G.L. Christensen, R.I. Dick, Specific resistance measurements: nonparabolic data, Journal of Environmental Engineering 111 (1985) 243-257.

[5] R. Kerekes, R. Soszynski, T. Doo, The flocculation of pulp fibres, Papermaking Raw Materials: Their Interaction with the Production Process and Their Effect on Paper Properties-Transactions of the Eighth Fundamental Research Symposium held at Oxford: September 1985, Mechanical Engineering Publications Limited, 1985, pp. 265-310, 1009. [6] R. Kerekes, C. Schell, Regimes by a Crowding Factor, Journal of pulp and paper science 18 (1992) J32-38.

[7] R. Soszynski, R. Kerekes, Elastic interlocking of nylon fibres suspended in liquid, part 2: process of interlocking, Nord. Pulp Pap. Res. J 3 (1988) 180-184.

[8] D. Martinez, K. Buckley, S. Jivan, A. Lindstrom, R. Thiruvengadaswamy, J. Olson, T. Ruth, R. Kerekes, Characterizing the mobility of papermaking fibres during sedimentation, The science of papermaking: transactions of the 12th fundamental research symposium, Oxford. The Pulp and Paper Fundamental Research Society, Bury, UK, 2001, pp. 225-254. [9] D. Martinez, H. Kiiskinen, A.-K. Ahlman, R. Kerekes, On the mobility of flowing papermaking suspensions and its relationship to formation, Journal of Pulp and Paper Science 29 (2003) 341-347.

[10] J. Sall, A. Lehman, M. Stephens, L. Creighton, S.S. JMP, A Guide to Statistics and Data Analysis Using Jmp, SAS Institute (2012).

[11] R. Simard, L. Morissette, M. Barbe, Screw press washing of a southern pine CTMP, Pulping Conference:[proceedings](USA), 1988, pp. 381-390.

[12] H. Hill, J. Edwards, L. Beath, Curlated pulp-A new approach to pulp processing, Tappi 33 (1950) 36-44.

[13] D. Page, R. Seth, B. Jordan, M. Barbe, Curl, crimps, kinks and microcompressions in pulp fibres: Their origin, measurement and significance, Paper making raw materials: their interactions with the production process and their effect on paper properties. Transactions of the 8th Fundamental Research Symposium, 1985, pp. 183-227.

[14] J.A. Wieters, Screw press washing of a hardwood pulp, Tappi 40 (1976) 667-671. 